\title{
The Analysis of the Structure Nash Equilibrium Solution of Two-person Two-strategy Game*
}

\author{
Hongxia Fu, Jinghui Yang, Guochun Tang \\ School of Economic Management Shanghai, Second Polytechnic University, Shanghai 201209, China
}

\begin{abstract}
The paper discusses the solution of 2-person 2strategy game in consideration that has the pure strategy equilibrium point of Nash, and adopts the underline method to get the equilibrium points of Nash considering the possibility that the gains of 2-person are equal at the first. The paper lists 81 kinds' states through the exhaustive method, and summarizes 6 kinds of independence situations: non-equilibrium point of Nash, oneequilibrium point of Nash, three-equilibrium point of Nash, fourequilibrium point of Nash for each one, and two-equilibrium point of Nash for two. In the meantime the paper gives the case of game for repairing the railway or the road for explaining the 6 kinds of equilibrium point of Nash. In the end, the paper draws a conclusion that the equilibrium points of Nash are not optimal solutions.
\end{abstract}

Index Terms - equilibrium points of Nash, analytic of the structure, under line method, pure strategy

Nash equilibrium, also known as a non cooperative game equilibrium, is an important term of game theory, named after John Nash. Nash balance refers to the situation that the game, for each participant, as long as the other people do not change strategy, he will not be able to improve your situation. Suppose that there are n players who participate in the game, given the strategies of the others conditions, their own optimal strategy choose each bureau (individual optimal strategy may depend on the may not be dependent on others' strategy), so as to maximize their interests. One strategy of all bureaus constitutes a strategy combination (Strategy Profile). Nash equilibrium refers to such a strategy; this strategy is composed of all persons involved in the optimal strategy. At a given others strategy case, no one has enough reason to break the balance. Nash equilibrium, in essence, is a kind of non cooperative game state.

\section{Game Two Two Decision}

\subsection{The establishment of game model of two $2 * 2$ two decision Helpful Hints}

In P1 there are two decision denoted as D11 and D12; in P2 there are two decision denoted by D21 and D22.Remember the state $\mathrm{V} 11=\{\mathrm{D} 11, \mathrm{D} 21\}, \mathrm{V} 12=\{\mathrm{D} 11, \mathrm{D} 22\}, \mathrm{V} 21=\{\mathrm{D} 12$, $\mathrm{D} 21\}, \mathrm{V} 22=\{\mathrm{D} 12, \mathrm{D} 22\}$. In Pi in the Vij income is denoted as $\mathrm{Ri}$ (Vij) (i=1,2). The following diagram model:

\begin{tabular}{c|c|c|}
\multicolumn{3}{c}{$\mathrm{P}_{2}$} \\
\cline { 2 - 3 } $\mathrm{P}_{1}$ & $\mathrm{~V}_{11} \mathrm{R}_{2}\left(\mathrm{~V}_{11}\right)$ & $\mathrm{V}_{12} \mathrm{R}_{2}\left(\mathrm{~V}_{12}\right)$ \\
$\mathrm{R}_{1}\left(\mathrm{~V}_{11}\right)$ & $\mathrm{R}_{1}\left(\mathrm{~V}_{12}\right)$ \\
\cline { 2 - 3 } & $\mathrm{V}_{21} \mathrm{R}_{2}\left(\mathrm{~V}_{21}\right)$ & $\mathrm{V}_{22} \mathrm{R}_{2}\left(\mathrm{~V}_{22}\right)$ \\
$\mathrm{R}_{1}\left(\mathrm{~V}_{21}\right)$ & $\mathrm{R}_{1}\left(\mathrm{~V}_{22}\right)$ \\
\hline
\end{tabular}

\subsection{Two two independent decisions Nash equilibrium state is proposed}

"Compared with underline" exhaustive above four kinds of state benefits for both sides size, we found that there are 81 possible Nash equilibrium state. Through the analysis, a rare consists of 6 independent states. The first is Nash equilibrium; second to three Nash equilibrium solutions; third to four Nash equilibrium solutions; fourth for no equilibrium Nash; fifth species, sixth are two of Nash equilibrium solution. See below:

The first state

\begin{tabular}{|c|c|}
\hline $\mathrm{V}_{11} \underset{\mathrm{R}_{1}\left(\mathrm{R}_{11}\right)}{\underline{\mathrm{R}_{2}}\left(\mathrm{~V}_{11}\right)}$ & $\begin{array}{c}\mathrm{V}_{12} \quad \mathrm{R}_{2}\left(\mathrm{~V}_{12}\right) \\
\mathrm{R}_{1}\left(\mathrm{~V}_{12}\right)\end{array}$ \\
\hline $\begin{array}{cc}V_{21} & R_{2}(V 21) \\
& R_{1}\left(V_{21}\right)\end{array}$ & $\begin{array}{c}\mathrm{V}_{22} \quad \mathrm{R}_{2}\left(\mathrm{~V}_{22}\right) \\
\mathrm{R}_{1}\left(\mathrm{~V}_{22}\right)\end{array}$ \\
\hline
\end{tabular}

The second state

\begin{tabular}{|c|c|}
\hline $\mathrm{V}_{11} \underline{\mathrm{R}_{2}\left(\mathrm{~V}_{11}\right)}$ & $\mathrm{V}_{12} \underline{\mathrm{R}_{2}}\left(\underline{\mathrm{V}}_{12} \underline{\mathrm{V}}_{12}\right)$ \\
\hline $\mathrm{V}_{21} \frac{\mathrm{R}_{2}\left(\mathrm{~V}_{21}\right)}{\underline{\mathrm{R}}_{1}\left(\mathrm{~V}_{21}\right)}$ & $\begin{array}{c}\mathrm{V}_{22} \quad \mathrm{R}_{2}\left(\mathrm{~V}_{22}\right) \\
\mathrm{R}_{1}\left(\mathrm{~V}_{22}\right)\end{array}$ \\
\hline
\end{tabular}

The third state

\begin{tabular}{|c|c|}
\hline $\mathrm{V}_{11} \underset{\mathrm{R}_{2}}{\underline{\mathrm{R}}_{2}}\left(\mathrm{~V}_{11}\right)$ & $\mathrm{V}_{12} \underline{\mathrm{R}_{2}\left(\mathrm{~V}_{12}\right)}$ \\
$\underline{\mathrm{R}}_{1}\left(\underline{\mathrm{V}}_{11}\right)$ & $\underline{\mathrm{R}}_{1}\left(\mathrm{~V}_{12}\right)$ \\
\hline $\mathrm{V}_{21} \underline{\mathrm{R}_{2}}\left(\underline{\mathrm{V}}_{21}\right)$ & $\mathrm{V}_{22} \mathrm{R}_{2}\left(\mathrm{~V}_{22}\right)$ \\
$\underline{\mathrm{R}}_{1}\left(\mathrm{~V}_{21}\right)$ & $\mathrm{R}_{1}\left(\mathrm{~V}_{22}\right)$ \\
\hline
\end{tabular}

The fourth state

\begin{tabular}{|c|c|}
\hline $\begin{array}{c}\mathrm{V}_{11} \quad \mathrm{R}_{2}\left(\mathrm{~V}_{11}\right) \\
\mathrm{R}_{1}\left(\mathrm{~V}_{11}\right)\end{array}$ & $\begin{array}{c}\mathrm{V}_{12} \quad \mathrm{R}_{2}\left(\mathrm{~V}_{12}\right) \\
\mathrm{R}_{1}\left(\mathrm{~V}_{12}\right)\end{array}$ \\
\hline $\begin{array}{cc}\mathrm{V}_{21} & \mathrm{R}_{2}\left(\mathrm{~V}_{21}\right) \\
\mathrm{R}_{1}\left(\mathrm{~V}_{21}\right)\end{array}$ & $\begin{array}{cc}\mathrm{V}_{22} & \mathrm{R}_{2}\left(\mathrm{~V}_{22}\right) \\
\mathrm{R}_{1}\left(\mathrm{~V}_{22}\right)\end{array}$ \\
\hline
\end{tabular}

The fifth state

\begin{tabular}{|c|c|}
\hline $\mathrm{V}_{11} \underline{\mathrm{R}_{1}\left(\mathrm{R}_{2}\left(\mathrm{~V}_{11}\right)\right.}$ & $\begin{array}{cc}\mathrm{V}_{12} & \mathrm{R}_{2}\left(\mathrm{~V}_{12}\right) \\
\mathrm{R}_{1}\left(\mathrm{~V}_{12}\right)\end{array}$ \\
\hline $\begin{array}{c}\mathrm{V}_{21} \quad \mathrm{R}_{2}\left(\mathrm{~V}_{21}\right) \\
\mathrm{R}_{1}\left(\mathrm{~V}_{21}\right)\end{array}$ & $\begin{array}{c}\mathrm{V}_{22} \quad \mathrm{R}_{2}\left(\mathrm{~V}_{22}\right) \\
\mathrm{R}_{1}\left(\mathrm{~V}_{22}\right)\end{array}$ \\
\hline
\end{tabular}

The sixth state

\begin{tabular}{|c|c|}
\hline $\mathrm{V}_{11} \underline{\mathrm{R}}_{1}\left(\underline{\mathrm{R}}_{11}\left(\mathrm{~V}_{11}\right) \underline{11}\right)$ & $\mathrm{V}_{12} \frac{\mathrm{R}_{2}}{\mathrm{R}_{1}}\left(\mathrm{~V}_{12}\right)$ \\
\hline $\begin{array}{c}\mathrm{V}_{21} \quad \mathrm{R}_{2}\left(\mathrm{~V}_{21}\right) \\
\mathrm{R}_{1}\left(\mathrm{~V}_{21}\right)\end{array}$ & $\begin{array}{cc}\mathrm{V}_{22} & \mathrm{R}_{2}\left(\mathrm{~V}_{22}\right) \\
\mathrm{R}_{1}\left(\mathrm{~V}_{22}\right)\end{array}$ \\
\hline
\end{tabular}

*This work is partially supported by the Discipline Construction Project (No. XXKPY1313) of Shanghai Second Polytechnic University. 


\section{Nash Equilibrium Analysis of Case}

\section{1 classic case, Nash equilibrium: the prisoner's dilemma}

The prisoner's dilemma the following is an example of. (In 1950, the mathematician Tucker as a visiting professor at Stanford University, in his speech to some psychologists, about two prisoners story.)

Suppose there are two thief A and B co offenders, private homes were caught by the police. The police will be two people were placed in two different rooms within the trial, each of the suspects, the police give policy is: if a suspect to confess to the crime, handing over the goods, so the irrefutable evidence, two people were found guilty. If the other suspects also confessed, two people were each sentenced to 8 years in prison; if another crime suspicion person not confess it to deny, the crime of obstructing (because there is evidence that the guilty) and another 2 years, but frankly the active commuted to 8 years, the immediate release. If two people are denied, then the police because of insufficient evidence cannot be sentenced two people stealing, but can enter private homes. Two people who will be sentenced to jail for 1 year.

The prisoner's dilemma game

B

\begin{tabular}{|c|c|c|}
\hline & Frank & Deny \\
\hline Frank & $\begin{array}{c}\mathrm{V}_{11} 8 \\
-8\end{array}$ & $\begin{array}{c}\mathrm{V}_{12}-10 \\
0\end{array}$ \\
\hline Deny & 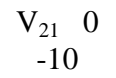 & 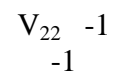 \\
\hline
\end{tabular}

About the case, clearly the best strategy is to deny the both sides, everyone was sentenced to only 1 years. But because of the two people in the isolated state, should first of all from the psychological point of view, the parties will believe that the other will betray themselves in order to protect; the second will be starting from the selfserving purpose to choose. The two men will have such a thought process: if he frankly, if I deny, may take 10 years in prison if I confess, up to 8 years; if he were to deny, if I deny, I will be sentenced to a year, if I frankly can be released, and he will sit 10 years in prison. Considering the above, whether he is honest or not, is me to confess it. Two people will move the brain, eventually, two people have chosen to confess, and the results were sentenced to 8 years in prison.

Based on the economics of "rational person" assumption, two prisoners in accordance with their own interests is the choice of confession, was beneficial to both sides of the strategy is not confession which were released will not appear. These two strategies are to choose honest and outcome was sentenced to 8 years, the Nash equilibrium is starting from the self-serving purpose, the double-edged sword, neither self nor he. This case is the first state: a Nash equilibrium solution.

\subsection{The actual case in basic construction: building the highway or railway built?}

A place for the improvement of economic level, traffic flow increased significantly, the original railway, and highway has been unable to meet the needs of economic development. Construction of railway and highway construction belong to different departments; two departments have to maintain the status quo and the new extension Railway (highway) were analyzed:

The first possibility, if both sides to maintain the status quo in the saturated state each had 5 points; a new expansion, one party to maintain the status quo were 8 points, 2 points; both the new extension, each 5 points.

\begin{tabular}{|c|c|c|}
\hline & \multicolumn{2}{|c|}{ B } \\
\hline & Railway & maintain \\
\hline Freeway & $\mathrm{V}_{11} 5$ & $\begin{array}{cc}\mathrm{V}_{12} & 2 \\
\underline{8} & \end{array}$ \\
\hline Maintain & $\begin{array}{c}\mathrm{V}_{21} 8 \\
2\end{array}$ & $\begin{array}{cc}\mathrm{V}_{22} & 5 \\
\underline{5} & \end{array}$ \\
\hline
\end{tabular}

From here you can see that this is the first state: a Nash equilibrium solution. The game result is to maintain the status quo, non-destructive to the interests of both sides. But bad for society.

Second may, if both sides to maintain the status quo in the saturated state each had 5 points; the new highway expansion, due to increase in traffic can score 10 points, railway status quo, still 5 points; if the new extension railway, because of high cost, the comprehensive score of 8 , the highway to maintain the status quo is still 5 points; both are new expansion of Highway 7 points to 8 points, the railway.

B

\begin{tabular}{|c|c|c|}
\hline & Railway & maintain \\
\hline Freeway & $\begin{array}{r}\mathrm{V}_{11} \underline{\underline{8}} \\
7\end{array}$ & $\begin{array}{c}\mathrm{V}_{12} \underline{\underline{5}} \\
\underline{\underline{10}}\end{array}$ \\
\hline Maintain & $\begin{array}{r}\mathrm{V}_{21} \underline{\underline{8}} \\
\underline{\underline{5}}\end{array}$ & $\begin{array}{r}\mathrm{V}_{22} \\
\underline{\underline{5}}\end{array}$ \\
\hline
\end{tabular}

You can see from the picture above this into second states: three Nash equilibrium solutions. Nash equilibrium solution from both the new extension of the situation.

Third may, if both sides to maintain the status quo in the saturated state each had 5 points; the new highway expansion, had 10 points; if the new extension railway, because of high cost, the comprehensive score of 8 .

\begin{tabular}{|c|c|c|}
\hline & \multicolumn{2}{|c|}{ B } \\
\hline & Railway & maintain \\
\hline Freeway & $\begin{array}{c}\mathrm{V}_{11} \underline{\underline{8}} \\
\underline{\underline{10}}\end{array}$ & $\begin{array}{c}\mathrm{V}_{12} \underline{\underline{5}} \\
\underline{\underline{10}}\end{array}$ \\
\hline Maintain & $\mathrm{V}_{21} \underline{\underline{5}} \underline{\underline{8}}$ & $\mathrm{~V}_{22} \underline{\underline{5}}$ \\
\hline
\end{tabular}


You can see from the picture above this into third States: four Nash equilibrium solutions. Nash equilibrium solution contains both all possible.

\subsection{Nash equilibrium in the game}

The two game player A, B flip a coin, if A, B are positive or negative, $\mathrm{A}-1, \mathrm{~B}+1$; if $\mathrm{A}$, contrary to $\mathrm{B}, \mathrm{A}+1, \mathrm{~B}-1$.

B

\begin{tabular}{|c|c|c|}
\hline & Positive & Negative \\
\hline Positive & $\mathrm{V}_{11}+1$ & $\mathrm{~V}_{12}^{\mathrm{V}^{2}}-1$ \\
\hline Negative & $\begin{array}{c}\mathrm{V}_{21}-1 \\
\underline{+1}\end{array}$ & $\mathrm{~V}_{22}+1$ \\
\hline
\end{tabular}

Finally, did not ask cashier what equilibrium solution, this is the fourth state.

\subsection{Business price war: high or low?}

The two companies A, B in the production of a product, and both for the replacement goods. If both the high price strategy each had 92 points; if both sides adopt low-cost strategy each had 98 points; if a party at a low price, high price, who had 90 points, 96 points at low prices.

B

$$
\text { Low price High price }
$$

A

\begin{tabular}{|l|c|c|}
\cline { 2 - 3 } Low price & $\mathrm{V}_{11} \underline{98}$ & $\mathrm{~V}_{12} 90$ \\
High price & $\underline{98}$ & 96 \\
\cline { 2 - 3 } & $\mathrm{V}_{21} 96$ & $\mathrm{~V}_{22} \underline{\underline{90}}$ \\
& $\underline{90}$ & $\underline{92}$ \\
\hline
\end{tabular}

The Nash equilibrium of such means both alone cannot change the price, on the other side does not change the price conditions, they cannot price, otherwise it will further loss of market; cannot be price cuts, because there will be a sale. This is fifth kinds of state: two Nash equilibrium solutions. So the two companies can change the original pattern of interests, evaluate the allocation scheme through negotiations to seek new profit, appear score new: if A, B are low, the A 98, B 96; A price, B price, A 90, B 96, B; A price, A 98, B 93; both are high, A, Beach 92 points.

B

Low price High price

A

\begin{tabular}{|c|c|}
\hline $\mathrm{V}_{11} \underline{\underline{96}}$ & $\mathrm{~V}_{12} \underline{93}$ \\
$\underline{\underline{98}}$ & $\underline{98}$ \\
\hline $\mathrm{V}_{21} \underline{\underline{96}}$ & $\mathrm{~V}_{22} 92$ \\
90 & 92 \\
\hline
\end{tabular}

This is the sixth independent state of Nash equilibrium: two Nash equilibrium solutions. One change, does not affect the benefit of another.

\section{Conclusions}

Nash equilibrium theory laid the foundation of modern game theory and economic theory, to change the system and the structure of economics. Noncooperation game theory concept, content, model and analysis tool has penetrated into most of the economic subject fields, change the content and structure of these disciplines, these disciplines as basic research paradigm and theoretical analysis tools, thus changing the original connotation of each branch of economic theory in the system. Expanded the scope of economics to study economic issue, analysis method of Nash equilibrium and the related model, provides an analysis tool for economists in depth.

Strengthen the economics research depth, forming system research paradigm based on the classic game. That can be a variety of problems or economic relations, classified according to type or feature classic game, and studied according to the analysis method and model of the corresponding classical game, will make a field experience easy to transplant to another field. To expand and strengthen the economics and other social science, natural science association. Nash equilibrium is great, because it is common, but common to almost everywhere. Behavior theory of Nash equilibrium is applied to humans; other organisms are also suitable for human survival, outside of the laws of motion and development. The role of a bridge and Nash equilibrium of game theory, the economics and other social sciences, natural sciences closer together, forming a virtuous cycle economics and other disciplines and promote each other.

Of course, Nash equilibrium was reached, does not mean that the game both in stationary state, in order to game in this equilibrium is reached in game action and reaction in the continuous. Nash equilibrium does not mean that the game both parties reach an overall optimal state.

\section{References}

[1] E.N.Barron, "GAME THEORY An Introduction", Wiley \& Sons, Inc. 2008

[2] Noam Nisan, Tim Rough garden, Eva Taros, Vijay V. Vazirani, "Algorithmic Game Theory", Cambridge University Press, 2007.

[3] Wang Zeke, "understanding the Nash equilibrium of the game", higher education press, 2009.

[4] fudenberg. Economic game theory. Shanghai: Fudan University press, 2006.

[5] Robert Gibbons. Peak. Basis of game theory. Beijing: China Social Science Publishing House, 1999.

[6] Fu Junhua, Chen Huixiong. A new interpretation of. Economic Forumhappy theory of prisoner's dilemma, 2009 (7). 